\title{
Pengaruh Sabut Kelapa sebagai Bahan Tambah Campuran AC-BC Menggunakan Batu Gunung Barani
}

\author{
Retor Rante Tondok ${ }^{* 1}$, Alpius ${ }^{* 2}$, Monika Datu Mirring Palinggi ${ }^{3}$ \\ *1 Mahasiswa Program Studi Teknik Sipil, Universitas Kristen Indonesia Paulus Makassar, \\ Indonesia retorrante95146@gmail.com \\ *2,3 Dosen Program Studi Teknik Sipil, Universitas Kristen Indonesia Paulus Makassar, Indonesia ${ }^{2}$ \\ alpiusnini@gmail.com ${ }^{* 2}$ dan monikadatumirring@gmail.com ${ }^{* 3}$
}

Corresponding Author: monikadatumirring@ukipaulus.ac.id

\begin{abstract}
Abstrak
Salah satu pemanfaatan Sabut Kelapa sebagai campuran beraspal, saat ini sudah banyak digunakan berbagai macam bahan tambah untuk meningkatkan mutu campuran beraspal. Penelitian ini dimaksudkan untuk mengetahui karakteristik campuran AC-BC yang memakai bahan tambah Sabut Kelapa dan juga untuk mengetahui pengaruh Sabut Kelapa pada campuran AC-BC. Metode yang digunakan yaitu perendaman Marshall konvensional diperoleh campuran AC-BC dengan kadar Sabut Kelapa sebagai bahan tambah yaitu $0 \%, 1 \%, 2 \%, 3 \%, 4 \%$ dengan kadar aspal 5\%. Adapun pengaruh karakteristik pada tiap komposisi campuran yaitu jika kadar Sabut Kelapa bertambah, maka nilai Stabilitas diperoleh 1300,74-2354,10 dan VFB 72,28-75,70 dimana semakin meningkat, sedangkan untuk nilai VIM 4,18-3,52, Flow 3,50-2,33 dan VMA 15,08-14,49 dimana semakin menurun. Dari hasil pengujian dapat disimpulkan bahwa campuran AC-BC dengan menggunakan bahan tambah Sabut Kelapa telah memenuhi sepesifikasi umum bina marga 2018.
\end{abstract}

Kata kunci: Karakteristik, Sabut Kelapa, AC-BC, Marshall.

\begin{abstract}
One of the uses of Coconut Coir as a paved mixture, currently has been widely used a variety of added ingredients to mixtures. This study is intended to find out the characteristics of $A C$-BC mixtures that use coconut coir added ingredients and also to find out the AC-BC mixture. The method used is conventional Marshall immersion obtained ac-BC mixture with coconut coir content as a added material that is $0 \%, 1 \%, 2 \%, 3 \%, 4 \%$ with asphalt content of $5 \%$. As for the characteristic influence on each mixed composition, if the level of Coconut Coir increases, then the stability value is obtained 1300.74-2354.10 and VFB 72.28-75.70 which is increasing, while for vim values 4.18-3.52, flow 3.502.33 and VMA 15.08-14.49 which decreases. From the test results it can be concluded that the AC-BC mixture using the added ingredients of Kelapa Cout has fulfilled the general specification of bina marga 2018.
\end{abstract}

Keywords: Characteristics, Coconut Coir, AC-BC, Marshal

\section{PENDAHULUAN}

Pada saat ini kebutuhan akan jalan raya semakin meningkat sehingga diperlukan kualitas perkerasan yang baik mengingat banyaknya kerusakan jalan yang disebabkan oleh tonase kendaraan atau beban kendaraan yang berlebihan (over load) dan masuknya air pada campuran beraspal. Jalan yang rusak kelembaban menyebabkan pengelupasan, yaitu terpisahnya lapisan aspal dari partikel agregat akibat hilangnya daya rekat 
antara aspal dengan permukaan agregat. Oleh sebab itu, penggunaan bahan tambah (additive) dan filler menjadi salah satu alternatif yang diharapkan dapat meningkatkan kualitas campuran beraspal .

Seiring dengan perkembangan teknologi material khususnya pekerjaan perkerasan jalan, muncul ide untuk memanfaatkan bahan-bahan yang tak terpakai atau limbah sebagai bahan penyusun dan bahan tambah pada campuran beraspal [1]. Salah satunya pemanfaatan Sabut Kelapa sebagai campuran beraspal. Saat ini sudah banyak digunakan berbagai macam bahan tambah untuk meningkatkan mutu campuran beraspal.

Kemajuan teknologi tentang bahan perkerasan jalan dari tahun ke tahun semakin meningkat terutama dalam penggunaan material yang berasal dari alam yang digunakan sebagai bahan utama dalam campuran perkerasan jalan. Gunung Barani adalah gunung yang terletak di Kelurahan Manggau yang kaya akan sumber alamnya berupa material batuan yang dapat digunakan sebagai bahan perkerasan jalan.

Penelitian tentang pengunaan serabut kelapan sebagai bahan lapisan permukaan jalan antara lain "Analisis Pengaruh Penggunaan Abu Sabut Kelapa Sebagai Filler Pada Campuran Aspal Retona Blend 55”. Diperoleh hasil penelitian pengaruh filler 4,5\%-6,25\%. [2]. "Uji Durabilitas Campuran AC-WC Menggunakan Kombinasi Limbah Plastik Dan Abu Serabut Kelapa Sebagai Filler". Diperoleh hasil penelitian Nilai KAO yaitu, 5,31-5,81. [3]. "Analisis Karakteristik Campuan Aspal Beton Menggunakan Kombinasi Semen Denga Cangkang Lokan dan Sabut Kelapa Sebagai Filler". Diperoleh hasil penelitian nilai KAO yaitu untuk variasi 1 4,1\%-4,9\% dan variasi 2 4,8\%-4,4\%. [4]. "Pengaruh Penambahan Limbah Serabut Kelapa Sawit Pada Campuran Asphalt Treated Base ATB Ditinjau Dari Nilai Parameter Marshall Test”. Rancangan komposisi untuk campuran AC-WC adalah agregat kasar 37,20\%, agregat halus 51,40\%, dan filler 5,54\%. [5]. "Durabilitas Campuran AC-BC Yang Menggunakan Batu Gunung Baba Kabupaten Tana Toraja”. Diperoleh hasil penelitian menunjukkan nilai Stabilitas yaitu 1167,61 kg-1015,66 kg, untuk Flow yaitu 3,3 mm-3,8 mm, dan untuk Durabilitas yaitu 95,49\%-86,99\%. [6]. "Pemanfaatan Limbah Styrofoam Sebagai Bahan Tambah Campuran AC-BC yang Menggunakan Sungai Bittuang”. Diperoleh hasil penelitian stabilitas, aliran, rongga yang terisi aspal (VFB), rongga campuran (VIM) dan rongga agregat (VMA) memenuhi spesifikasi jalan raya Menghasilkan jumlah aspal yang optimal. [7]. "Durabilitas Campuran Laston Lapis Antara Menggunakan Agregat Sungai Salassa Kab Toraja Utara”. Diperoleh hasil penelitian menunjukkan nilai Stabilitas yaitu 1276,68 kg-1235,43 kg, untuk Flow yaitu 2,7 mm-3,2 mm, dan untuk Durabilitas yaitu 97,44\%-80,62\%. [8]. "Penggunaan Agregat Sungai Batu Tiakka' Pada Campuran $A C-B C$ ”. Diperoleh hasil penelitian karakterisitik agregat kasar 43,18\%, agregat halus 46,27\%, filler 5,55\%, dan kadar aspal 5,0\%. [9]. "Kajian Penggunaan Batu Gunung Barani Untuk Bahan Campuran AC-BC". Diperoleh hasil penelitian karakterisitik agregat kasar 43,00\%, agregat halus 46,00\%, filler 5,00\%, dan kadar aspal 5,50\%. [10]. "Penggunaan Batu Sungai Seriti Kab Luwu Pada Campuran AC-BC”. Diperoleh hasil penelitian karakterisitik agregat kasar 42,82\%, agregat halus 45,73\%, filler 5,45\%, dan kadar aspal 6,00\%. [11].

Penelitian ini bertujuan untuk mengetahui karakteristik campuran AC-BC yang memakai bahan tambah Sabut Kelapa dan juga untuk mengetahui pengaruh Sabut Kelapa pada campuran AC-BC. Metode yang digunakan yaitu perendaman Marshall konvensional diperoleh campuran AC-BC dengan kadar Sabut Kelapa sebagai bahan tambah yaitu $0 \%, 1 \%, 2 \%, 3 \%, 4 \%$ dengan kadar aspal $5 \%$.

\section{METODOLOGI}

\section{Lokasi Pengambilan Material}

Agregat yang akan digunakan berasal dari Gunung Barani yang terletak di Kelurahan Manggau. Material diambil dengan sekop dan dikemas ke dalam karung, kemudian dibawa ke Laboratorium Jalan dan Aspal UKI Paulus Makassar untuk diuji. 


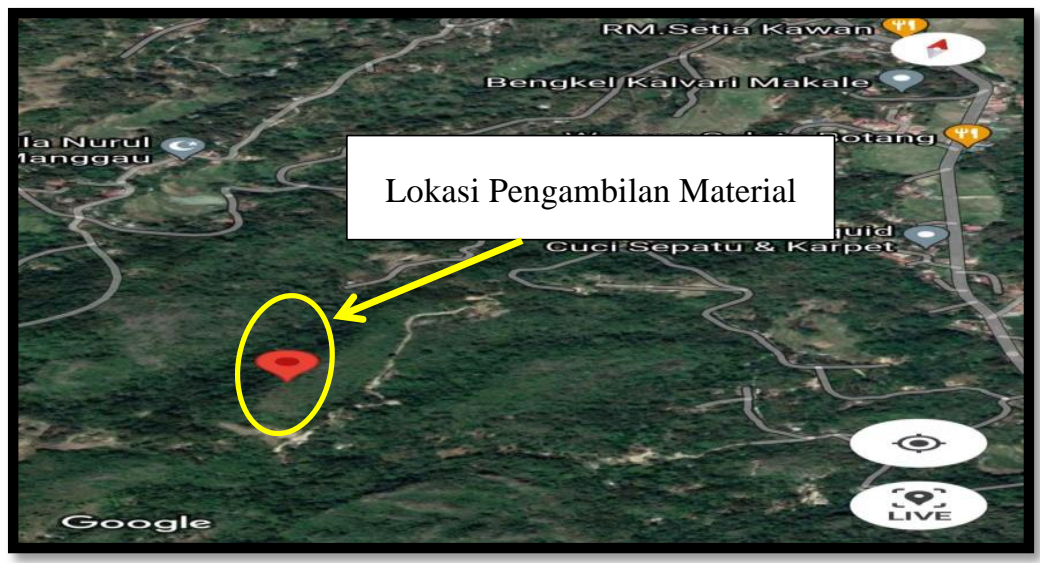

Gambar 1. Lokasi pengambilan agregat ( $\left.3^{\circ} 07^{\prime} 46.3^{\prime \prime} \mathrm{S} 119^{\circ} 51^{\prime} 17.1^{\prime \prime} \mathrm{E}\right)$

\section{Komposisi Campuran AC-BC}

Material dan Bahan yang akan digunakan untuk campuran aspal beton adalah :

a. Agregat diambil dari Gunung Barani.

b. Aspal sebagai Bahan pengikat (aspal penetrasi 60/70).

c. Sabut Kelapa sebagai bahan tambah.

d. Bahan pengisi (filler) berasal dari semen.

Komposisi campuran AC-BC dengan bahan tambah Sabut Kelapa yang digunakan pada penelitian sebelumnya yang dilakukan oleh Ivon Tambing, 2020, untuk menentukan jumlah bitumen yang tepat sehingga campuran dan komposisi aspal dapat diperoleh sesuai dengan persyaratan spesifikasi.

\section{Perancangan Komposisi Campuran AC-BC}

Tabel 1. Komposisi Campuran AC-BC (Kadar Aspal 5,00\%)

\begin{tabular}{|c|c|c|c|c|c|c|c|c|c|c|}
\hline \multicolumn{2}{|c|}{ Ukuran saringan } & \multicolumn{4}{|c|}{ Lolos Saringan } & \multicolumn{3}{|c|}{ Tertahan Saringan } & \multicolumn{2}{|c|}{$\begin{array}{c}\text { Komposisi } \\
\text { Campuran }(\%)\end{array}$} \\
\hline Inchi & $\mathrm{Mm}$ & \multicolumn{3}{|c|}{ Spesifikasi (\%) } & $\begin{array}{c}\text { Gradasi } \\
\text { Campuran } \\
(\%)\end{array}$ & $\begin{array}{c}\text { Proporsi } \\
(\%)\end{array}$ & $\begin{array}{c}\text { Proporsi } \\
\text { Dalam } \\
\text { Campuran } \\
(\%) \\
\end{array}$ & $\begin{array}{c}\text { Berat Dalam } \\
\text { Campuran } \\
(\mathrm{gr})\end{array}$ & & \\
\hline $1 \frac{1}{2} "$ & 37,500 & & & & & & & & \multirow{6}{*}{43,18} & \multirow{6}{*}{$\begin{array}{c}\text { Agregat } \\
\text { Kasar }\end{array}$} \\
\hline $1 "$ & 25,000 & \multicolumn{3}{|c|}{100} & 100,00 & & & & & \\
\hline $3 / 4 "$ & 19,000 & 90 & - & 100 & 95,00 & 5 & 4,55 & 54,55 & & \\
\hline $1 / 2 "$ & 12,500 & 75 & - & 90 & 82,50 & 12,5 & 12,05 & 144,55 & & \\
\hline $3 / 8 "$ & 9,500 & 66 & - & 82 & 74,00 & 8,5 & 8,05 & 96,55 & & \\
\hline No.4 & 4,750 & 46 & - & 64 & 55,00 & 19 & 18,55 & 222,55 & & \\
\hline No.8 & 2,360 & 30 & - & 49 & 39,50 & 15,5 & 15,05 & 180,55 & \multirow{6}{*}{46,27} & \multirow{6}{*}{$\begin{array}{c}\text { Agregat } \\
\text { Halus }\end{array}$} \\
\hline No.16 & 1,180 & 18 & - & 38 & 28,00 & 11,5 & 11,05 & 132,55 & & \\
\hline No.30 & 0,600 & 12 & - & 28 & 20,00 & 8 & 7,55 & 90,55 & & \\
\hline No.50 & 0,300 & 7 & - & 20 & 13,50 & 6,5 & 6,05 & 72,55 & & \\
\hline No.100 & 0,150 & 5 & - & 13 & 9,00 & 4,5 & 4,05 & 48,55 & & \\
\hline No. 200 & 0,075 & 4 & - & 8 & 6,00 & 3 & 2,55 & 30,55 & & \\
\hline \multicolumn{5}{|c|}{ Pan (filler) } & & 6 & 5,55 & 66,55 & 5,55 & Filler \\
\hline \multirow{2}{*}{\multicolumn{5}{|c|}{ Aspal }} & 5,00 & & 5,00 & 60,00 & 5,00 & Aspal \\
\hline & & \multicolumn{4}{|c|}{ Total } & 100 & 100,00 & 1200 & 100 & \\
\hline
\end{tabular}




\section{Persiapan Sampel Campuran AC-BC}

Persiapan material meliputi agregat yang dikumpulkan dari Gunung Barani Kelurahan Manggau berupa material batuan, kemudian dilakukan pemecahan material batuan Gunung Barani di Laboratorium Jalan dan Aspal UKI-Paulus Makassar untuk mendapatkan ukuran agregat yang dibutuhkan sesuai dengan standar / spesifikasi campuran AC-BC.

\section{Pemeriksaan/Pengujian Campuran AC-BC Untuk Tes Marshall Konvensional}

Pengujian Marshall Konvensional untuk campuran AC-BC harus sesuai dengan prosedur pada SNI 062489-1991 (Metode Pengujian Campuran Aspal Dengan Alat Marshall). Hasil pengujian Marshall campuran aspal menunjukkan untuk mendapatkan karakteristik serta pengaruh campuran dengan penambahan sabut kelapa dengan sifat-sifat nilai yang didapatkan dari Stabilitas, Flow, VMA, VIM dan VFB.

\section{ANALISA DAN PEMBAHASAN}

\section{Karakteristik campuran}

\section{a. Analisis terhadap Stabilitas}

Dengan Menggunakan kadar Sabut Kelapa 0\%, 1\%, 2\%, 3\%, dan 4\% diperoleh nilai stabilitas untuk kadar Sabut Kelapa 0\% sebesar 1300,74 Kg, untuk kadar Sabut Kelapa 1\% mengalami kenaikan sebesar 1611,96 Kg, untuk kadar Sabut Kelapa 2\% mengalami kenaikan sebesar 1998,82 Kg, untuk kadar Sabut Kelapa 3\% mengalami kenaikan sebesar 2302,23 Kg, dan untuk kadar Sabut Kelapa 4\% mengalami kenaikan sebesar 2354,10 Kg. Semua nilai stabilitas dengan bahan tambah Sabut Kelapa telah memenuhi Spesifikasi Umum Bina Marga 2018. Dari nilai stabilitas yang semakin meningkat ini dapat dilihat bahwa nilai stabilitas tertinggi diperoleh dari campuran berkadar Sabut Kelapa 4\% yaitu 2354,10 Kg. Berdasarkan Grafik di bawah, dapat disimpulkan bahwa semakin banyak kadar sabut kelapa yang digunakan maka semakin tinggi pula nilai Stabilitas yang didapatkan, begitupun sebaliknya.

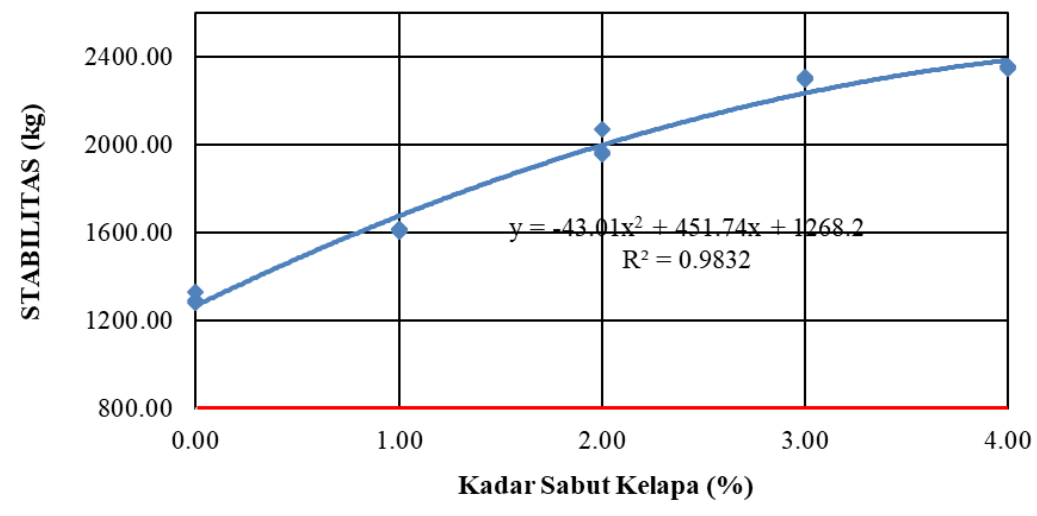

Gambar 2. Hubungan Kadar Sabut Kelapa terhadap stabilitas

\section{b. Analisa terhadap VIM (Void in Mix)}

Dengan menggunakan kadar Sabut Kelapa 0\%, 1\%, 2\%, 3\%, dan 4\% diperoleh nilai VIM untuk kadar Sabut Kelapa 0\% sebesar 4,18\%, untuk kadar Sabut Kelapa 1\% mengalami penurunan sebesar 4,09\%, untuk kadar Sabut Kelapa 2\% mengalami penurunan sebesar 3,91\%, untuk kadar Sabut Kelapa 3\% mengalami penurunan sebesar 3,61\%, dan untuk kadar Sabut Kelapa 4\% mengalami penurunan sebesar 3,52\%. Semua nilai VIM dengan bahan tambah Sabut Kelapa telah memenuhi Spesifikasi Umum Bina Marga 2018. Berdasarkan 
Grafik di bawah, dapat disimpulkan semakin tinggi kadar Sabut Kelapa yang digunakan maka nilai VIM yang didapatkan semakin kecil begitu pula sebaliknya.

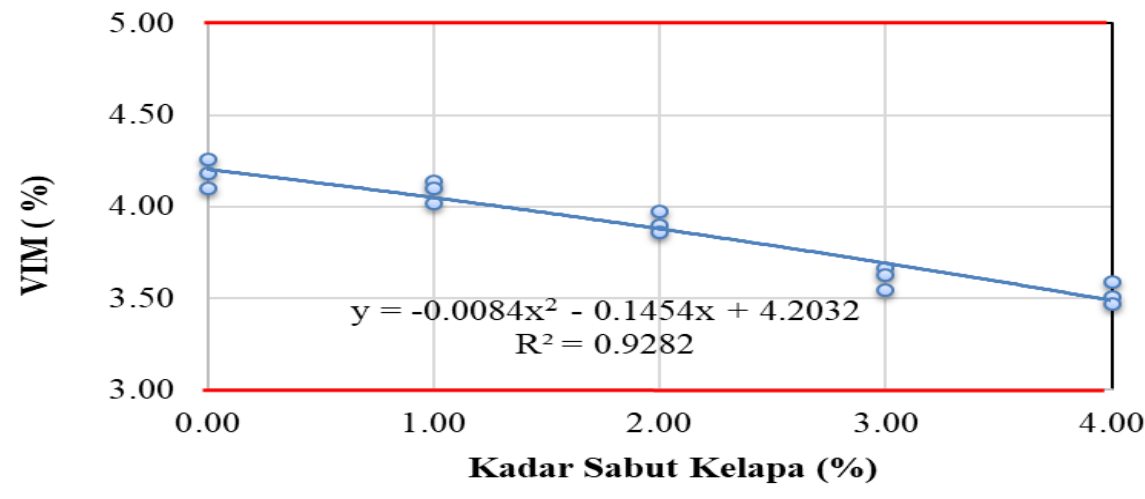

Gambar 3. Hubungan Kadar Sabut Kelapa terhadap VIM

\section{c. Analisa terhadap Flow}

Dengan menggunakan kadar Sabut Kelapa 0\%, 1\%, 2\%, 3\%, dan 4\% diperoleh nilai Flow untuk kadar Sabut Kelapa 0\% sebesar 3,50 mm, untuk kadar Sabut Kelapa 1\% mengalami penurunan sebesar 3,13 mm, untuk kadar Sabut Kelapa 2\% mengalami penurunan sebesar 2,83 mm, untuk kadar Sabut Kelapa 3\% mengalami penurunan sebesar 2,63 mm, dan untuk kadar Sabut Kelapa 4\% mengalami penurunan sebesar 2,33 mm. Semua nilai Flow dengan bahan tambah Sabut Kelapa memenuhi Spesifikasi Umum Bina Marga 2018. Berdasarkan Grafik di bawah ini, dapat ditarik kesimpulan bahwa semakin banyak kadar Sabut Kelapa yang digunakan dalam campuran beraspal maka semakin rendah pula nilai Flow yang didapatkan, begitupun sebaliknya.

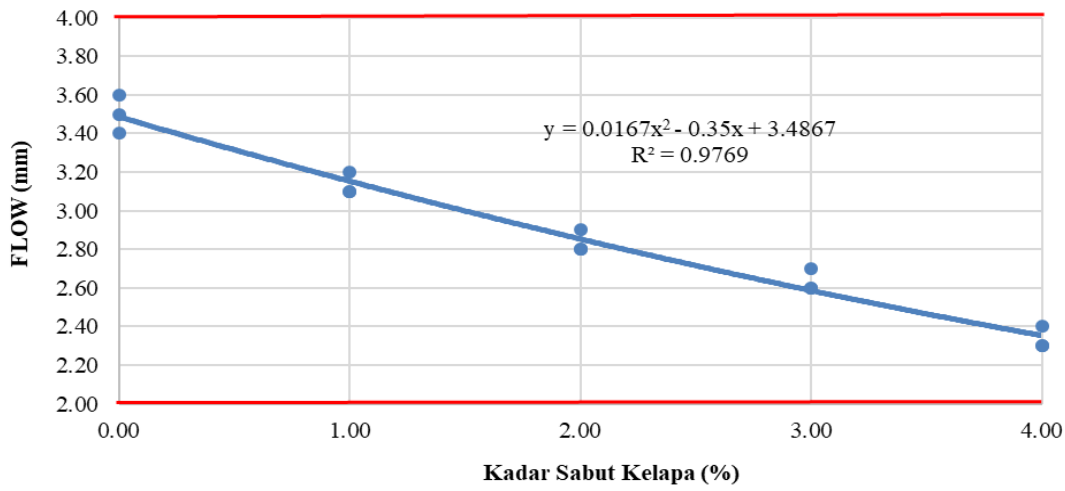

Gambar 4. Hubungan Kadar Sabut Kelapa dan Flow

\section{d. Analisa terhadap VMA (Void in Mineral Aggregate)}

Dengan menggunakan kadar Sabut Kelapa 0\%, 1\%, 2\%, 3\%, dan 4\% diperoleh nilai VMA untuk kadar Sabut Kelapa 0\% sebesar 15,08\%, untuk kadar Sabut Kelapa 1\% mengalami penurunan sebesar 14,99\%, untuk kadar Sabut Kelapa 2\% mengalami penurunan sebesar 14,84\%, untuk kadar Sabut Kelapa 3\% mengalami penurunan sebesar 14,57\%, dan untuk kadar Sabut Kelapa 4\% mengalami penurunan sebesar 14,49\%. Semua nilai VMA dengan bahan tambah Sabut Kelapa telah memenuhi Spesifikasi Umum Bina 
Marga 2018. Berdasarkan Grafik di bawah ini dapat dibuat kesimpulan bahwa semakin tinggi kadar Sabut Kelapa yang digunakan maka nilai VMA yang diperoleh semakin kecil, begitu pula sebaliknya.

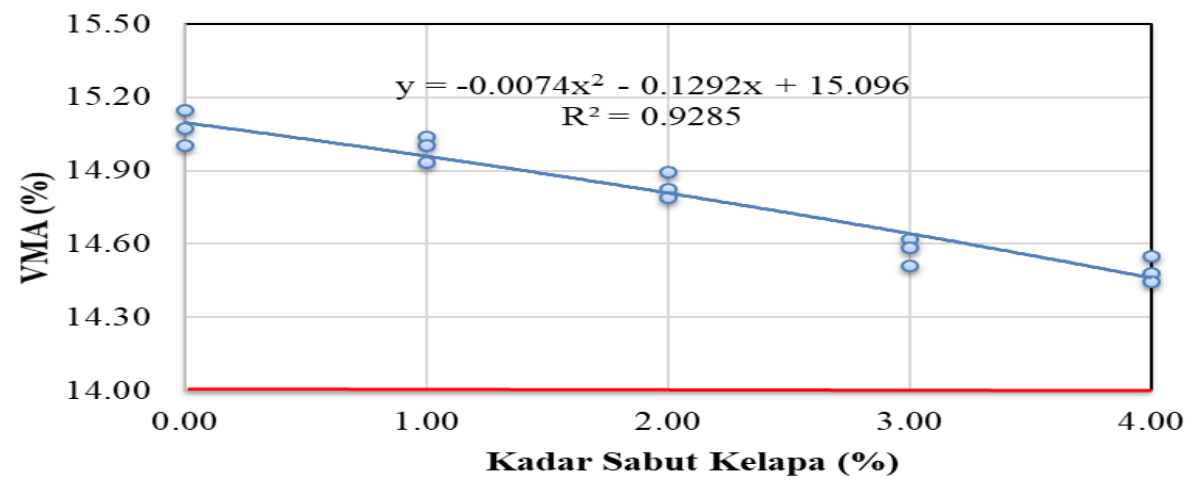

Gambar 5. Hubungan Kadar Sabut Kelapa terhadap VMA

\section{e. Analisa terhadap VFB (Void Filled with Bitumen)}

Dengan Menggunakan kadar Sabut Kelapa 0\%, 1\%, 2\%, 3\%, dan 4\% diperoleh nilai VFB untuk kadar Sabut Kelapa 0\% sebesar 72,28\%, untuk kadar Sabut Kelapa 1\% mengalami kenaikan sebesar 72,74\%, untuk kadar Sabut Kelapa 2\% mengalami kenaikan sebesar 73,64\%, untuk kadar Sabut Kelapa 3\% mengalami kenaikan sebesar 73,64\%, dan untuk kadar Sabut Kelapa 4\% mengalami kenaikan sebesar 75,70\%. Semua nilai VFB dengan bahan tambah Sabut Kelapa telah memenuhi Spesifikasi Umum Bina Marga 2018. Berdasarkan Grafik di bawah ini, dapat disimpulkan bahwa semakin banyak kadar Sabut Kelapa yang digunakan maka semakin tinggi pula nilai VFB yang diperoleh, begitu pula sebaliknya.

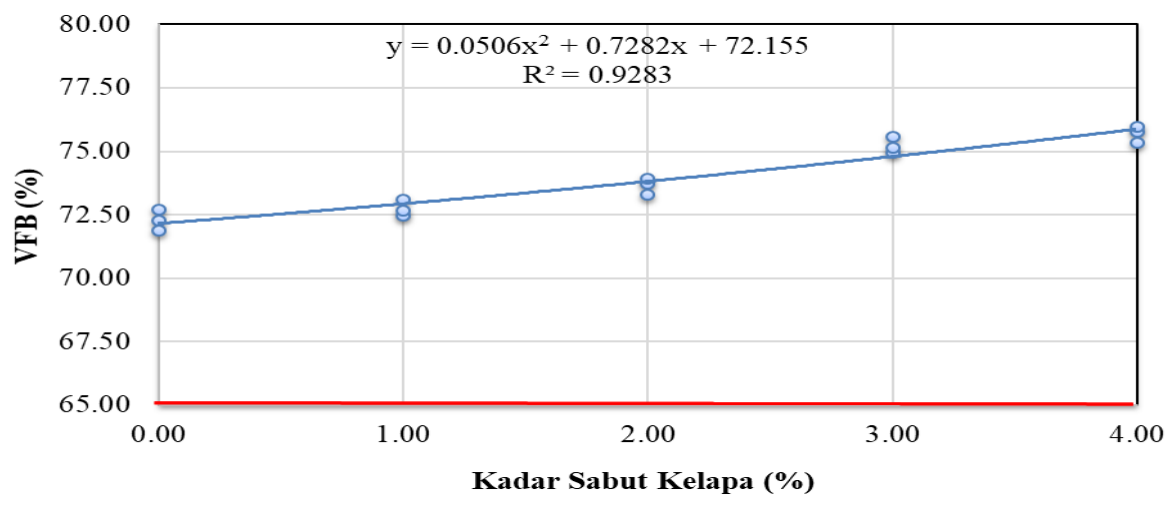

Gambar 6. Hubungan Kadar Sabut Kelapa dan VFB

\section{KESIMPULAN}

1. Hasil pengujian Marshall Konvensional campuran AC-BC menggunakan Batu Gunung Barani dengan bahan tambah Sabut Kelapa diperoleh karakteristik campuran beraspal yaitu Stabilitas, Flow, VIM, VMA, dan VFB. Berdasarkan pengujian di Laboratorium didapatkan kadar Sabut Kelapa yang direkomendasikan untuk digunakan adalah $4 \%$ hal itu dikarenakan pada kadar tersebut didapatkan nilai Stabilitas tertinggi. Dimana semua nilai karakteristik tersebut telah memenuhi Standar Spesifikasi Bina Marga 2018.

2. Pengaruh penambahan Sabut Kelapa pada campuran beraspal AC-BC dapat mengisi rongga-rongga dalam campuran sehingga rongga menjadi lebih kecil dan membuat ikatan antar agregat makin kuat 
sehingga campuran beraspal, hal ini dikarenakan akibat semakin besar kadar sabut kelapa yang digunakan. Campuran beraspal tersebut menjadi lebih kedap air dan cuaca, serta dapat menahan beban lalu lintas.

\section{DAFTAR PUTAKA}

[1] L. D. R. K. Salle, "Pemanfaatan Limbah," in Pemanfaatan Material Alternatif (Sebagai Bahan Penyusun Konstruksi), Makassar, Tohar Media, 2021, pp. 59 - 67.

[2] M. Safriani and D. Febrianti, "Analisis Pengaruh Penggunaan Abu Sabut Kelapa Sebagai Filler Pada Campuran Aspal Retona Blend 55," Jurnal Teknik Sipil Fakultas Teknik Universitas Teuku Umar, vol. 2, no. 2, pp. 69-78, 2016.

[3] Ondriani, S. M. Saleh and M. Isya, "Uji Durabilitas Campuran Ac-Wc Menggunakan Kombinasi Limbah Plastik Dan Abu Serabut Kelapa Sebagai Filler," Jurnal Teknik Sipil Universitas Syiah Kuala, vol. 1, no. 3, pp. 679-688, 2018.

[4] Veranita, B. Tripoli and H. Kesuma, "Analisis Karakteristik Campuran Aspal Beton Menggunakan Kombinasi Semen Dengan Cangkang Lokan Dan Sabut Kelapa Sebagai Filler," Jurnal Teknik Sipil Universitas Syiah kuala, vol. 9, no. 1, pp. 1-9, 2020.

[5] Y. Yahya, E. Priskasari and E. I. Imananto, "Pengaruh Penambahan Limbah Serabut Kelapa Sawit Pada Campuran (Asphalt Treated Base) Atb Ditinjau Dari Nilai Parameter Marshall Test," Student Journal GELAGAR, vol. 2, no. 2, pp. 200-207, 2020.

[6] C. Pasilaputri, Alpius and L. E. Radjawane, "Durabilitas Campuran AC-BC yang Menggunakan Batu Gunung Baba Kabupaten Tana Toraja," Jurnal Teknik Sipil UKI Paulus-Makassar, vol. 3, no. 3, pp. 361-367, 2021.

[7] N. Sambo, R. Rachman and Alpius, "Pemanfaatan Limbah Styrofoam Sebagai Bahan Tambah Campuran AC-BC Yang Mengggunakan Sungai Bittuang," Jurnal Teknik Sipil UKI Paulus- Makassar, vol. 3, no. 3, pp. 330-340, 2021.

[8] C. J. G. Salempa, Alpius and C. Kamba, "Durabiltas Campuran Laston Lapis Antara Menggunakan Agregat Sungai Salassa Kabupaten Toraja Utara," Jurnal Teknik Sipil UKI Paulus-Makassar, vol. 3, no. 3, pp. 314-320, 2021.

[9] G. P. Palimbunga, R. Rachman and Alpius, "Penggunaan Agregat Batu Sungai Tiakka' pada Campuran AC-BC," Jurnal Teknik Sipil UKI Paulus-Makassar, vol. 2, no. 2, pp. 112-118, 2020.

[10] I. Tambing, Alpius and L. E. Radjawane, "Kajian Penggunaan Batu Gunung Barani Untuk Bahan Campuran ACBC," E-Jurnal Teknik Sipil UKI Paulus-Makassar, vol. 3, no. 1, pp. 40-46, 2021.

[11] V. Mangetan, R. Mangontan and Alpius, "Penggunaan Batu Sungai Seriti Kabupaten Luwu pada Campuran ACBC," E-Jurnal Teknik Sipil UKI Paulus-Makassar, vol. 3, no. 1, pp. 76-84, 2021.

[12] C. Kamba, "Agregat Dari Material Lokal," in Pemanfaatan Material Alternatif (Sebagai Bahan Penyusun Konstruksi), Makassar, Tohar Media, 2021, pp. 35 - 46. 